\title{
La economía de la ciudad de México en la perspectiva de la globalización
}

Daniel Hiernaux-Nicolas

UAM-Xochimilco

\section{Resumen}

El planteamiento central de este trabajo es la economía de la ciudad de México, la cual ha sufrido numerosas transformaciones, como resultante de diversos procesos: la apertura de la economía nacional al sistema económico mundial y la dificultad de adaptación de las empresas mexicanas tradicionales. Enése analizan en tres escalas los cambios económicos que afectan la ciudad y tienen profundas manifestaciones en su morfología misma: la escala global, los cambios en el nivel nacional regional, y finalmente, la escala local de la ciudad. En todos los casos, se trata de evidenciar que la ciudad pasa por una fase de considerables transformaciones de sus estructura, como resultado de los procesos económicos señalados. Posteriormente, se analizan dos tendencias nuevas: la tendencia a la regionalización de la economía de la ciudad de México, es decir la formación de una economía regional cuyo eje será la ciudad, y la selectividad de las nuevas formas económicas en el territorio urbano. La última parte del texto, delínea en forma breve, las implicaciones de las mencionadas transformaciones económicas sobre la gestión de la ciudad de México. 


\section{Introducción}

Los cambios en la economía mexicana ocurridos en los últimos quince años, han tenido profundas repercusiones en la organización del territorio, tanto en la relación del espacio nacional con el sistemamundo, como en las estructuras regionales. En relación a lo urbano, también asistimos a numerosos cambios, entre los que se destaca el crecimiento de las ciudades medias, la reestructuración de las actividades económicas de las ciudades y la tendencia a la modernización arquitectónica y urbanística, en particular en las áreas metropolitanas.

Los procesos de recomposición territorial, en las diferentes escalas mencionadas, se ven reflejados en las transformaciones recientes de la ciudad de México; éstos parecen, por su intensidad, superar los intentos anteriores de modernizar la ciudad, intentos que tuvieron lugar desde el porfiriato hasta fines de los años setenta.

Este trabajo se dedica a analizar las transformaciones económicas que han propiciado y orientado las profundas mutaciones en la estructura económica de la ciudad, su relación con el sistema nacional y que, de alguna manera, resultan reorganizadoras del espacio urbano.

\section{Factores de cambio en la economía de la ciudad de México}

En esta primera parte del ensayo, se hace hincapié en los grandes procesos detransformación de laestructura económica nacional, tanto en referencia a algunos cambios relativos a su integración al sistema mundial, como aquellos que afectan la configuración territorial del país y finalmente, también a los cambios locales que permiten vislumbrar un nuevo rostro para la economía de la ciudad de México.

Esta visión, por aproximaciones sucesivas a las diversas escalas territoriales, se propone (desde una concepción menos estratificada que lo que el procedimiento aquí propuesto puede dejar interpretar), plantear que existe una fuerte integración entre las escalas mundial o global, nacional-regional y local, a lo largo de las que se perfila una movilidad o desplazamiento de los efectos en forma ascendente y descendente en esas escalas, es decir desde lo local hasta lo mundial y, desde lo mundial a lo local pasando por lo regional (Hiernaux, 1997). De acuerdo a esto, también se recuperan algunos elementos de la teoría de los fractales, según la cual la totalidad se encuentra inmersa en las formas menores, planteamiento que algunos autores, como Tomas Villasante, manejan como un efecto de "holograma".

\subsection{Cambios económicos globales, procesos que impactan en la ciudad}

Los cambios económicos globales que vive México como pás, tuvieron sus primeras manifestaciones durante el auge petrolero, aunque en aquel entonces, no se acompañaron de una apertura económica. En aquellas circunstancias, la relación peso-dólar actuó de facto como un elemento que facilitó el incremento de las importaciones, inclusive de bienes de consumo, lo que puede interpretarse como una apertura de hecho. Por otra parte, los enormes excedentes de la renta petrolera permitieron que la ciudad de México entrara en una fase de modernización, expresada en la reactivación de la construcción del Metro, la habilitación de los ejes viales, la integración de nuevos edificios-faros, como la Torre de Pemex y el Hotel Presidente y finalmente, la construcción de nuevos centros comerciales, entre ellos Perisur. Esto propició un crecimiento importante de las actividades de la construcción, acompañadas de una participación relevante de sus empresarios en la vida política local y nacional.

Sin embargo, es a partir de 1982 cuando se consolidó una política de cambio sustancial en la economía nacional, no exclusiva de la esfera económica. Por ejemplo, si la década de los ochenta, a nivel internacional a veces ha sido definida por el "regreso del actor", nuestro país no ha sido ajeno a esta tendencia, observable particularmente en una mayor actuación de la sociedad civil y de los grupos organizados en la vida social, económica, política y cultural del pás. Los desafortunados eventos de septiembre de 1985 , colocaron a México en una situación más visible a nivel internacional, lo que desembocó en una creciente participación de grupos locales y ONGs en la vida política, cultural y social del país.

Es, indudablemente, a partir de la implantación de una política decididamente neoliberal en la esfera económica a fines de los ochenta, que se empezaron a desplegar nuevas relaciones económicas

1 Conferencia magistral del doctor Villasante en la Reunión de la Red Nacional de Investigación Urbana, Tlaxcala, 1997. Mientras que la referencia a los fractales implica que en cada dimensión o escala se encuentra la misma estructura que en los niveles superiores inferiores, la imagen del "holograma" usada por Villasante, remite a que en una representación en dos dimensiones del plano holográmico, podemos encontrar las tres dimensiones del volumen representado. 
que si bien involucraron al país en su conjunto, han tenido un particular impacto en la ciudad de México.

A manera de ejemplo mencionaremos los siguientes procesos vinculados a estas políticas neoliberales:

- La bursatilización de la economía nacional, reflejada en el peso creciente que adquirió el sector financiero en la economía. Lo anterior se tradujo en la construcción de la Bolsa de Valores, la modernización de las instituciones bancarias y la creación de sedes de prestigio, la mayor parte ubicadas en la ciudad de México. Además, se asistió a una participación creciente de las actividades financieras en la constitución del Producto Interno Bruto del Distrito Federal. No obstante, no todo el espacio metropolitano ha estado involucrado en estos procesos, son esencialmente las áreas centrales del Distrito Federal las que participaron y participan. ElProducto Interno Bruto de esta entidad, en 1988 estaba integrado en un $11.5 \%$ por los servicios financieros, seguros y sector inmobiliario, aunque en 1993 los mismos aportaban ya el $16.73 \%$ de su Producto Interno Bruto.

- Por otra parte, también debemos subrayar que flujos crecientes de inversión extranjera se dirigieron hacia el país. Si bien un componente importante se localizó materialmente en el interior del país (como es el caso de la industria maquiladora, la automotriz y el turismo), las sedes sociales de las empresas se ubicaron en la capital del país y particularmente en las delegaciones centrales de ésta. Así, de 9,932 empresas con capital extranjero ubicadas en la ciudad de México (Distrito Federal y 27 municipios conurbados), $92.1 \%$ se localizó en el Distrito Federal, particularmente en las delegaciones Miguel Hidalgo (34.8\%), Cuauhtémoc (25.3\%) y Benito Juárez (11.6\%). Los municipios conurbados han tenido un papel débil en la captación de empresas con capital extranjero, con sólo $7.9 \%$ de las empresas instaladas en la capital del país. ${ }^{2}$

- Las grandes empresas transnacionales que movilizan sus actividades en el sistema mundial, empezaron a instalar sus sedes en la ciudad de México; lo anterior se refleja, por ejemplo, en la progresiva concentración de las mayores empresas de México en algunas de las delegaciones del Distrito Federal, ocurrida entre 1989 y la actualidad. Para 1995, 325 empresas de las 500 empresas más grandes de México, tenían su sede en esta ciudad, o sea $65 \%$ del total, de las cuales $83.4 \%$ se localizan en el Distrito Federal. Dicho proceso de concentración en la entidad se ha acelerado durante el sexenio salinista, y se puede tomar como un indicador del papel creciente de la ciudad de México como un nodo del sistema mundial.

- Con respecto a esta última cuestión: la red de ciudades mundiales, sería útil distinguir entre las ciudades globales de primer orden, las de segundo y las de tercero. Dentro de las de primer orden, tal vez tendríamos que incluir las tres que ha identificado Sassen: Tokio, Nueva York y Londres (Sassen, 1991); entre las de segundo orden tendríamos a: París, Bruselas, Los Angeles, Miami, entre otras, tal como las clasifica John Friedmann (1995), y finalmente tenemos algunas ciudades globales de relevo, entre las cuales podemos incluir Sao Paulo, Johannesburg y la ciudad de México. ${ }^{3}$

Sin embargo, no pocos autores consideran que no es así, inclusive el propio Departamento del Distrito Federal, e: fechas recientes, elaboró un documento que señala lo contrario (DDF, 1997), es decir, que la ciudad de México no alcanza el rango de ciudad global. Nuestra interpretación es inversa, ya que nos parece más iluminadora la propuesta ya mencionada de distinguir tres órdenes de ciudades mundiales. Así, la ciudad de México puede ser considerada un centro dentro del sistema mundial, por presentar características propias de una ciudad global, aunque dentro de este sistema se ubica en un tercer orden.

En materia de comercio exterior, también se ha asistido a una fuerte concentración de los procesos de impor-

${ }^{3}$ Entre su primer trabajo de 1982 y la revisión del mismo tema de 1996, Friedmann parece dudar en cuanto a la clasificación de varias ciudades, entre las cuales están Sao Paulo y la ciudad de México, en el concierto de las ciudades mundiales (Friedmann, 1982 y 1996). Lo anterior puede explicarse a partir de la constatación que en 1981-82 ambas ciudades gozaban de un dinamismo sensible, resultado del auge petrolero entre otros factores, mientras que para 1995-96, se observa el efecto de la reestructuración de las economías metropolitanas a raíz del ajuste que afectó muy particularmente las grandes ciudades latinoamericanas. 
tación y exportación a partir de la ciudad de México. De hecho, desde la fase que podemos calificar como "economía cerrada" se dieron las condiciones para la centralización de las actividades de comercio exterior a partir de esta ciudad. Esta situación ha dado a la capital la ventaja competitiva del conocimiento del mercado y del manejo de los mecanismos de transferencia de bienes, que ha podido expandir sustancialmente en la fase posterior de la apertura. Sin embargo, lo anterior esconde algunas cuestiones no poco relevantes. Por ejemplo, el hecho de que muchos productos están registrados como producidos en la sede social de la empresa y no en el lugar de producción, como es el caso de las exportaciones automotrices registradas a partir de la sede social de las empresas.

- Aunque el tema de la cultura no es el central para esta presentación, puede plantearse que la constitución de una parte de la sociedad mexicana (por lo pronto, los sectores de mayores ingresos) como un mercado privilegiado para las industrias culturales globales, ha facilitado la expansión de dichas industrias en el país y particularmente en la ciudad de México. ${ }^{4}$ En este contexto, la política del Distrito Federal y la de la Federación, ha sido la de fortalecer las estructuras materiales de la cultura a partir de 1982. Ejemplos de ello pueden ser la remodelación del Auditorio Nacional, la instalación de nuevos museos en el eje de Reforma y la construcción del Centro Nacional de la Cultura y las Artes. Este proceso ha sido respaldado por el sector privado que encuentra en las expresiones culturales para las nuevas élites, un espacio de acumulación nada despreciable. Es por esto, que ciertos sectores privados han participado en la construcción de museos, aunque también en la reestructuración de los espacios cinematográficos y las salas de concierto. ${ }^{5}$ Asimismo, empresas de contratación de espectáculos, como OCESA por ejemplo, cumplen un papel decisivo en la proliferación de los nuevos

4 En otras grandes metrópolis se ha dado un proceso similar, véase el caso de Monterrey con el museo Marco, por ejemplo.

5 Cabe señalar también que la expansión de la cultura se manifiesta a otra escala, por jemplo, en la transformación de edificios céntricos, en la colonia Roma o en la Condesa, en nuevos espacios de la cultura y el consumo.

espacios públicos y las actividades culturales masificadas en la ciudad.

\subsection{Cambios nacionales-regionales y su relación con la ciudad de México}

No todos los cambios económicos más relevantes se asocian a los procesos propios de la escala global; por el contrario, muchas mutaciones de la economía encontraron cabida en las economías regionales (sin que ello suponga una desvinculación con lo global), de tal suerte que se ha replanteado la relación entre la capital del país y las regiones, al menos en ciertos ámbitos.

Durante varias décadas sólo la ciudad de México ofreció las condiciones adecuadas o ventajas comparativas para la localización industrial. Lo anterior, en buena medida, resultó de la adopción de un modelo cuasi fordista de conducción de la economía, que favoreció las plantas industriales de grandes dimensiones. Este tipo de plantas requirió de un mercado local abundante en mano de obra, así como también de un mercado de consumo amplio, ambas condiciones sólo existían en la ciudad de México. Esto impulsó a la creación de una fuerte base económica cuyo nivel de concentración interregional ya no necesita ser documentado (véase Garza, 1988, por ejemplo).

- Sin embargo, la petrolización de la economía marcó un primer cambio significativo, analizado particularmente por Hernández Laos (1984), que supuso la desconcentración de actividades claves hacia regiones alejadas, fueran las petroleras o fueran aquellas actividades basadas en factores locacionales relevantes como la disponibilidad de mineral de hierro y de cobre.

- En esta misma tónica, se asistió también a la dispersión de las actividades turísticas, en torno a grandes polos de inversión, en áreas de potencial turístico importante como el Pacífico o el Caribe (Hiernaux, 1988).

- El cambio más notorio surgió no tanto de los esfuerzos oficiales para promover dichos polos, política que ha demostrado ser poco eficaz en sus resultados, sino desde la modificación misma de los procesos productivos. En este contexto, la 
intensificación de los procesos neotaylorianos ${ }^{6}$ ha beneficiado a las áreas fronterizas de excepción y lo que en un momento fue un crecimiento por ventajas artificiales (las cláusulas del decreto de maquiladoras), progresivamente se hizo un crecimiento genuino a partir de la transformación de no pocos procesos productivos en cadenas de subcontratación que pudieron ser resueltos a bajo costo por la industria maquiladora.

No debe olvidarse que la industria maquiladora ha concentrado la mayor parte del crecimiento industrial, llegando no sólo a compensar la desindustrialización de la base económica tradicional de la ciudad de México, sino también a promover un crecimiento considerable del mercado de trabajo industrial. Como es muy conocido, es la frontera Norte la que ha resultado la más beneficiada a este respecto.?

- Por otro lado, la relación con la economía global que em prenden o consolidan no pocos sectores como la industria automotriz, la cervecera, la industria del cemento, la siderurgia, etcétera; tiende a valorizar las localizaciones regionales ubicadas al Norte del país o por lo menos a lo largo de las vías centrales, lo que se ha acostumbrado a llamar el "corredor Nafta".

- Todo lo anterior ha cambiado radicalmente la relación de la ciudad de México con las regiones de México. Por una parte, la evolución del PIB regional demuestra que las regiones antes periféricas se vienen constituyendo cada vez más centrales para el actual modelo de acumulación. Por otra, es imposible negar que se ha entrado a un sistema de competencia abierta, en el que el papel que juegan los poderes locales es esencial para la atracción de nuevos capitales (véase el caso de la General Motors en Silao, Guanajuato, por ejemplo). ${ }^{8}$

- Por procesos "neotaylorianos" nos referimos al modelo de organización del trabajo basado en el uso intensivo de mano de obra, baja intensidad de capital y escasa organización laboral (Véase Lipietz y Leborgne, 1989).

7 El volumen de empleo generado por la maquiladora supera los 700,000 puestos en la actualidad (Zedillo, 1997) y constituye más del $12 \%$ del empleo industrial total del pais.

${ }^{8}$ Si bien Silao parecería una ubicación interesante en el Centro Norte del país para una empresa ligada a la vez al mercado central del país y a la exportación, no es menos cierto que existían localizaciones alternas como San Luis Potosí, Querétaro o Celaya, que ofrecían
- El redespliegue industrial significa que la economía de la ciudad de México ya no presenta el carácter concentrador que dominó durante mucho tiempo, aunque no por ello deja de mantener una significativa centralización, cuestión señalada anteriormente. La concentración del Producto Interno Bruto en el Distrito Federal se ha reducido considerablemente, por lo menos hasta 1988, pero contradictoriamente, de 1988 a 1993, se acentuó la concentración como parte de la reactivación de la ciudad de México, como eje rector de la economía nacional. Así, para 1970 la participación del Distrito Federal en el Producto Interno Bruto fue del $27.6 \%$, cifra que alcanzó un mínimo en 1985 , con sólo $20.96 \%$. En 1988, esta participación se incrementó ligeramente al $21.4 \%$, sufriendo una fuerte aceleración en 1993, con $24.1 \%$ del total nacional. ${ }^{9}$

- Esta última situación ha cambiado en un plazo muy breve los desequilibrios que conoció el país durante mucho tiempo en la distribución de la población en el territorio. Todo parece indicar que, los reacomodos demográficos son más rápidos de lo esperado; algunos procesos claves pueden ser observados. Por una parte, se viene dando un freno al ritmo de crecimiento de la ciudad de México, evidenciado desde $1987 .{ }^{10} \mathrm{La}$ ciudad de México no es -y posiblemente no será- la ciudad más grande del mundo. En segundo lugar, se observa una redistribución de la población emigrante de la ciudad hacia las ciudades interiores, en parte por la emigración de las clases medias y alta que parecería están liderando parcialmente los procesos de crecimiento regional (es sólo una hipótesis que debería ser estudiada a fondo en distintos casos).

- Los cambios económicos antes mencionados también tienen una fuerte influencia sobre los procesos políticos, a partir de

condiciones similares de accesibilidad. De hecho es la oferta de ventajas específicas (la perforación de pozos de agua garantizando un abasto esencial en un estado con fuertes carencias de agua) por parte del gobierno estatal panista de Medina Placencia, que determinó la selección del sitio por parte de la empresa.

${ }^{9}$ Estimaciones propias con base en información del INEGI, varios años.

${ }^{10}$ La Encuesta Nacional de Empleo Urbano de 1987 permitió demostrar que la tendencia migratoria hacia la ciudad de México, había adquirido en años recientes una orientación contraria, con más emigración que inmigración a la capital de la República (CONAPO, 1995). 
las elecciones federales de 1988 que, recíprocamente también resultaron influidos por los procesos políticos. El avance del Partido de Acción Nacional, particularmente en el Norte del país, parece articularse con esta hipótesis, mientras que el avance del Partido de la Revolución Democrática parecería obedecer más a un voto de insatisfacción frente a un destino económico no muy claro, como pasa en el Distrito Federal y en los estados de la Región Centro, así como en Guerrero.

- Finalmente, los procesos de redistribución de la población y las actividades económicas tienen otra cara, como es la difusión de los problemas tradicionales del Distrito Federal y de la ciudad de México en conjunto hacia las regiones y las ciudades medias. Por ejemplo, se han incrementado en éstas la contaminación, la violencia, pero también los modos de vida propios de la ciudad de México. Esto último ha tenido por efecto que las ciudades medias se parezcan cada vez más a los suburbios de la capital, por lo pronto en la esfera cultural, en la forma urbanística que asume su proceso de crecimiento demográfico-urbano, ${ }^{11} \mathrm{y}$ muy particularmente en los patrones de consumo.

\subsection{Cambios locales y el nuevo rostro de la economía capitalina}

La ciudad de México tuvo que enfrentar las consecuencias de la apertura económica, traducida en una fuerte presión por parte de la competencia para introducir productos a bajos precios en el mercado nacional. La falta de medidas gubernamentales de apoyo, así como la decisión de llevar a cabo el proceso sin negociación con el sector empresarial y en plazos reducidos, produjo una fuerte incapacidad en el sector productivo para responder a la agresiva competencia de empresas de la economía mundial.

$\mathrm{Al}$ abrir las fronteras en un momento de aguda crisis de la economía (fines de los ochenta), se minimizó aún más la capacidad de respuesta del sector empresarial, entre otras razones, por su ya alto

"A este respecto, es particularmente interesante observar que en la mayor parte de las llamadas ciudades medias de crecimiento demográfico sustentado, se han extendido los fraccionamientos residenciales periféricos, centros comerciales y complejos de multicines, posiblemente también por la influencia de la migración importante de capitalinos hacia dichas ciudades. nivel de endeudamiento, la crisis de pago de dichas deudas, la imposibilidad de contratar financiamiento para la modernización de las plantas industriales, etcétera.

Aún no se han realizado investigaciones que analicen en detalle los sectores más afectados. Particularmente, está pendiente la reconstrucción de un mapa minucioso de los impactos de la apertura y de la crisis de la economía metropolitana resultante.

Haciendo un balance entre 1970 y 1988 , se ha demostrado que algunos sectores de actividad evidenciaron cierto crecimiento a nivel del Área Metropolitana, mientras que otros registraron pérdidas importantes, que fueron determinantes para un descenso del empleo manufacturero en el Área Metropolitana de la ciudad de México (AMCM) (Williams, 1993). Gracias a este estudio de Williams, a pesar de que maneja información hasta 1988, se puede apreciar que el efecto de la apertura ha sido desigual en las diversas zonas que integran el Área Metropolitana de la ciudad de México, sus efectos territoriales han sido desiguales en su interior. A lo que se agrega la posibilidad de una superposición de efectos resultantes de la apertura (en ciertos territorios), con otros derivados de tendencias de largo plazo, como ha sido la progresiva desindustrialización del centro de la ciudad, particularmente en las cuatro delegaciones centrales de la ciudad.

El tema anterior, de alguna manera, nos introduce en la cuestión de la tendencia a la desindustrialización de la ciudad de México. En 1993, Connolly ya expresaba ciertas dudas respecto a este proceso. En cierta forma, existen dos argumentos centrales en relación al nivel de actividad industrial a considerar para evaluar esta materia. El primero se relaciona con el hecho de que la reconversión de muchas empresas, particularmente las más grandes, se asocia con la estrategia de restringir sus actividades a la producción central -el empleo manufacturero básico- mientras que numerosas actividades que podemos considerar como servicios a la producción, antes prestados por la misma empresa, se han transferido a empresas filiales o a subcontratistas (comolas actividades de vigilancia, servicios computacionales, gestión de comedores, servicios de limpieza, etcétera). La desindustrialización tendría, entonces, más relación con la forma como se ha registrado el empleo por sectores o subsectores, que con una verdaderá eliminación de empleos en la manufactura.

El segundo argumento que tiende también a mostrar la desindustrialización como un fenómeno de menor magnitud es el reconocimiento dela informalización o "clandestinización" creciente de una parte de las actividades manufactureras. Lo anterior es una hipótesis que no ha podido ser medida, aunque existen señales de que 
se ha incrementado la aparición de talleres clandestinos, particularmente en la periferia de la ciudad de México, tanto en ciertos municipios conurbados (como Ecatepec, Netzahualcóyotl, La Paz-Los Reyes, Chimalhuacan, Chalco, entre otros), como en las delegaciones periféricas del Distrito Federal (sería el caso de Tláhuac, Tlalpan o Xochimilco).

Sin embargo, también es posible concebir la desindustrialización de la ciudad desde otro punto de vista, como es la creciente terciarización de la economía metropolitana. La terciarización de la ciudad puede entenderse bajo dos ángulos: Uno es el de la transferencia de parte de la población, formalmente empleada y asalariada en la manufactura, hacia ciertos ámbitos de actividad marcados fuertemente por la informalidad. En el otro, no cabe duda que se asiste a un desarrollo de actividades terciarias ligadas a la "nueva economía", es decir a los sectores relativamente dinámicos dentro de la economía nacional y metropolitana.

También, es necesario señalar que la terciarización de la economía y la reconversión de la manufactura por medio de la subcontratación y la fragmentación empresarial y productiva, tienen consecuencias importantes para la fuerza laboral, como es la reducción del asalariamiento, la exclusión de las prestaciones sociales asociadas a este modo de remuneración y la flexibilización acrecentada de la vida laboral (contratos de trabajo más cortos, inestabilidad de las mismas empresas, salarios a destajo, etcétera). Lo anterior no deja de repercutir en una desinstitucionalización de las actividades económicas metropolitanas y en la transferencia de numerosos segmentos de la producción y de los mercados de trabajo a las "zonas grises", como las llama Minc (1993), es decir aquéllas en donde el control o la promoción institucional tienen pocas posibilidades de intervenir.

\section{Nueva configuración económica territorial de la ciudad de México}

En los párrafos que siguen intentamos hacer un balance del estado de la economía de la ciudad de México, en relación con la configuración territorial. Para ello, nos referimos a la tradicional definición de la zona metropolitana a partir de los 28 municipios conurbados y las 16 delegaciones del Distrito Federal, aunque también mencionamos algunos efectos económicos en el territorio, que se podrían calificar como de escala regional.

\section{1. ¿Una economía regionalizada?}

Existen indicios de que la economía de la ciudad de México ha desbordado al Área Metropolitana. En relación a este fenómeno se viene hablando de la conformación de una metápolis (Ascher, 1996), para referirse a la situación en la cual la ciudad se integra por nodos articulados entre sí a través de ejes, sin que forzosamente exista una continuidad espacial entre los nodos.

Este nuevo concepto urbano, el de metápolis, parece iluminador para comprender la situación que empieza a esbozarse en la ciudad de México. En efecto, se asiste a un crecimiento sumamente intenso de algunas ciudades de la región Centro a partir de procesos productivos que se desconcentran de la ciudad de México, aunque mantienen una estrecha relación con la misma. Es el caso de las ciudades de Toluca, Cuernavaca y Querétaro, mientras que otras como Puebla, Pachuca o Tlaxcala, no forzosamente están pasando por el mismo proceso.

Existen pocos instrumentos para verificar empíricamente estos procesos territoriales si no es a través de los flujos carreteros o telefónicos, a través del estudio de las relocalizaciones de algunas empresas o de la apertura de nuevas empresas sostenidas por el capital de las de la ciudad de México. En distintos foros de discusión sobre cuestiones regionales realizados en los últimos años, se ha tendido a apoyar esta hipótesis, aunque evidentemente estamos lejos de haber podido realizar comprobaciones o acercamientos empíricos.

¿Por qué consideramos relevante empezar a observar a la ciudad de México desde esta idea de la metápolis? En buena medida porque el destino de la ciudad de México en los próximos veinte años, parecería estar perfilándose más de carácter regional que metropolitano. Sea cual sea la denominación que se le asigne, la idea de la "región urbana", la de "metápolis", eventualmente la noción de "megalópolis", apuntan a la conformación de un sistema de economía territorial compleja, con la formación de redes de intereses, intercambio de productos y flujos de capitales crecientes entre componentes discontinuos en el territorio, que en este caso corresponde a la hasta ahora conocida como Región Centro.

Si está hipótesis resultara cercana a la realidad, se podría asistir en los próximos quince o veinte años a la redefinición del papel de la ciudad de México con relación al resto del territorio nacional, aunque también a su redefinición interna. Así, si acordamos que la ciudad de México se ha ido organizando con base en un modelo fundado en la concentración productiva y la centralización de las decisiones, parece 
muy posible que quede poco territorio para sostener un crecimitnto productivo futuro, mientras que se podría seguir profundizando su centralización. Lo anterior tendria serias implicaciones sobre varias fimensiones, por ejemplo en los mercados de trabajo locales (metropolitunos), en las condiciones de vida urbanas y en la necesidad de acondicionar y reasignar espacios, sitios, localizaciones, para otras finalidades productivas o de gestión

\section{Una economfir urbana selectiva en ef territorio}

La economia de la ciudad de México siempre ha estado segregada territorialmente. Por ejemplo, el Norte industrial, el Este reservado al proletariado urbano y el Sur y Oeste más especializados en las funciones residenciales de sectores sociales medios y altos. Sin embargo, algunos autores, como Claude Bataillon, han hablado informalmente de ella como una ciudad de tipo "clase media", por su relativa homogeneidad (Rubalcava y Schteingart, 1988).

Algunos de los resultados más radicales que surgen de la aplicación del nuevo modelo cconómico, es que la ciudad se está haciendo, y lo seguirá haciendo de no mediar polfticas de ordenamiento territorial metropolitano, mucho más segregada territorialmente que en el pasado. El Mapa 1 que presentamos pretende ilustrar este planteamiento.

Algunos indicadores de esta segregación territorial creciente que selecciona espacios y los valoriza, son los ejemplos siguientes:

- Conformación de Comedorvemodernzadosdealtarentabilidad immobiliaria. Se han definido como espacios productivos de alsa rentabilidad, a aquellos que se basan en actividades financieras $y$ de gestion, uhicados principalmente sobre el Paseo de la Reforma, a lo largo del cual se ha autorizado la construcción de edificios modernizantes, que albergan a las actividades cconomicas relevantes parael modelo economico actual. Se está formando asi, un corredor que parte desde el Centro Histórico sigue por el Paseo de la Reforma, incluyela zona de Polanco y llega hasta las Lomas. Bosques de las Lomas y Santa Fe. La prolongación de este cje hacia Toluci pareceria algo arbitraria, aunque si se observan las tendencias integradoras a nivel regional de has que hablibamos arriba, no lo es ranto. Las recientes declaraciones del gobierno del Distrito Federal respecto al arranque de proyectos ambicio-

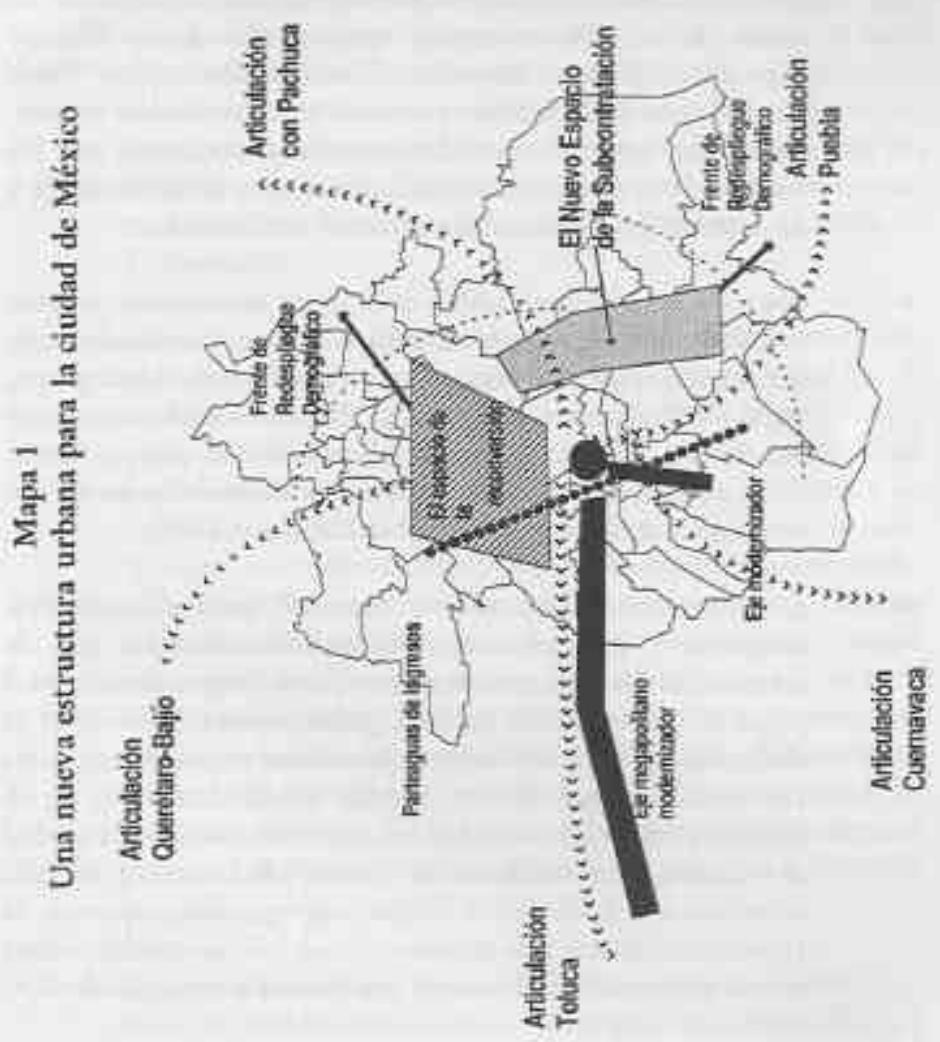


sos, entre otros, en los terrenos de la antigua planta de la General Motors en Polanco (febrero de 1998), apuntan hacia esta hipótesis de reforzamiento de un corredor de alta generación de valor agregado y modernizador.

En segundo lugar, la Avenida de los Insurgentes desde Reforma y hasta Perisur, y cada vez más hacia la entrada a la autopista a Cuernavaca, evidencia ser presa de actividades de creciente valorización con la construcción subsecuente de torres de lujo. Por ejemplo, recuperando el tan dilatado proyecto de la Torre del antiguo Hotel de México, hoy World Trade Center (WTC). El proyecto del WTC también se encuentra en una fase de expansión, por cierto rechazada por los vecinos de la zona, que aluden a los efectos contaminantes y de destrucción de su entorno barrial tradicional.

- Grandes centros comerciales. Los espacios de consumo se están constituyendo, para la población, en los puntos de referencia dentro del espacio urbano, por ejemplo, Galerías Insurgentes, Santa Fe, Perisur y recientemente Plaza Cuicuilco, son mojones del consumo urbano, incluido el cultural, para un sector de la población, que busca definir su identidad a partir del consumo, como lo señala García Canclini (1995).

- El sistema vial y las nuevas "arterias" para el transporte colectivo y para el automóvil privado, son los ejes de articulación de los corredores anteriores. Se mencionaba ya el papel de la Avenida de los Insurgentes, aunque también el de Reforma, Periférico y las propuestas de su segundo piso, la vía La Venta-Colegio Militar, además de sus funciones de alternativas al trafico regional, evitando su paso por la ciudad de México, son también las "venas" de la nueva retícula económica de la ciudad. A lo que se agregan las propuestas de trenes suburbanos y de enlace regional, que parecerían contar con la aceptación de la nueva gestión del Distrito Federal.

- Los centros urbanos. Las tendencias económicas con el tiempo pasan a constituir nuevas formas territoriales, situación que entendieron muy bien los responsables de la planificación de la ciudad de México durante el sexenio salinista. Su proyecto de ciudad es el reflejo del proyecto económico y la caja de resonancia de las desigualdades sociales promovidas por el mismo a escala nacional. Una de las manifestaciones de este proyecto salinista ha sido la revitalización de la idea de los centros urbanos formados por grandes proyectos modernizadores; idea que apareció desde inicios de los ochenta en la planeación urbana de la ciudad de México, sin mucho eco en la práctica en aquellos tiempos. ${ }^{12}$ Los proyectos Alameda, Centro Histórico y Xochimilco se enfrentaron a no pocas resistencias del vecindario, que desde la difusión del proyecto percibió una estrategia para desplazarlo más que para integrarlo a estos procesos de modernización. Varios de estos proyectos de centros urbanos se extinguieron rápidamente, sólo la transformación del Centro Histórico prosiguió, en parte por haberse sustentado en la estrategia de recuperar los edificios uno a uno, dificultando así una movilización barrial masiva como pasó en el caso del proyecto Alameda o Xochimilco.

- El nuevo Santa Fe. Este territorio se ha constituido en la mayor expresión de la posmodernidad metropolitana en la ciudad de México, en el sentido de reunir en un "espacio-isla", no hace mucho ocupado por "basurales", varias condiciones destacadas, como: una arquitectura de fin de siglo, formas de consumo y oferta de servicios que podrían considerarse "lujosas" en ciudades como Nueva York, altísima especulación inmobiliaria, infraestructuras monumentales y de muy acelerada construcción, por mencionar sólo algunos rasgos que impactan el nuevo paisaje urbano levantado sobre los antiguos basurales. Es significativo que este proyecto se ubique en las afueras de la ciudad, modificando radicalmente el centro de gravedad de la economía terciaria de la ciudad, así como radicalizando la tendencia alaconcentración residencial y de servicios para los sectores de altos ingresos en el Oeste de la ciudad.

- La periferia maquiladorizada. Por otra parte, están los espacios que marcan la otra cara de la segregación urbana, si es que podemos hablar de "otra cara", más bien, se trata de muchas

${ }^{12}$ La propuesta de Centros y Subcentros urbanos aparece en el Plan Regulador de Desarrollo Urbano del Distrito Federal de 1982, y fue retomada como una de las propuestas sustanciales del Programa de Reordenación Urbana y Protección Ecológica (PRUPE) de 1987. A partir de esa fecha, han sido un ingrediente obligado de la planeación tecnocrática de la ciudad. 
caras. Por una parte está el "Este cercano" es decir Netzahualcóyotl, Los Reyes-La Paz y las áreas aledañas, que se transforman cada vez más en los espacios de la subcontratación, la economía "maquiladorizada", no maquiladora pero si neotayloriana. ${ }^{13}$ Este crecimiento transforma lo que fue la primera periferia de los años sesenta, en un espacio en proceso de creciente valorización económica, aunque sea mediante sistemas de sobreexplotación de su mano de obra, que determinan así la "ventaja competitiva" de estas áreas para la atracción de nuevas fuentes de empleo. Entre otras cosas, esto muestra la necesidad de revisar el concepto de "periferia" entendido por sus funciones habitacionales para los sectores sociales de bajos ingresos. Los territorios de la periferia metropolitana parecen expresar una mayor integración a la economía de la ciudad, aunque esto sea a través de un modelo altamente segregado y "salvaje" en sus formas de explotación del trabajo.

- La expansión metropolitana tentacular. La presión de distintos sectores para la extensión de estos espacios económicos es considerable y se extiende sobre el Este metropolitano, pero también en algunos espacios rurales externos al AMCM, como es el caso de Tlalmanalco y Amecameca por el Sureste del Valle de México; esta expansión también alcanza a San Martín de las Pirámides, por el Noreste. De tal suerte que parecería desdibujarse un espacio económico específico, que se prolonga a lo largo de las vías principales, por ejemplo la carretera Chalco-Cuautla, creando un espacio semirural o semiurbano, de subcontratación informal y frecuentemente doméstica. Una reflexión similar cabe para los espacios que se extienden a lo largo de la conexión a Pachuca o hacia Tepozotlán (Villa del Carbón, etc.), por citar otros ejemplos.

- Los baldios industriales o "friches urbaines". Finalmente, no se pueden dejar de considerar como parte del actual mosaico de la ciudad, otra forma de expresión territorial de la reestructuración de la economía metropolitana, que ha actuado por desmembramiento de la economía industrial de la periferia metropolitana a través del cierre de unidades de producción. Este proceso ha empezado a crear "baldíos industriales" ("friches urbaines"), es decir espacios otrora industriales, hoy no recuperables para otro tipo de actividades debido al cierre de antiguas empresas. Estos baldíos se ubican, esencialmente, en los municipios conurbados correspondientes a la primera industrialización sustitutiva de las importaciones, así como también en las delegaciones de industrialización tradicional, tales como Azcapotzalco y Gustavo Madero, esencialmente.

\subsection{Reacomodos que son economía en sí}

Los reacomodos y reasignaciones de espacios de la ciudad, es decir, la apropiación de antiguos espacios para nuevos usos, implican destinar nuevos nichos económicos. Así, se ha podido observar que el sector de la construcción ha resultado altamente beneficiado por las políticas de reestructuración de la ciudad de México, como se observa en la evolución de la composición del Producto Interno Bruto del Distrito Federal entre 1988 y 1993. La construcción ha cumplido un papel central en estas asignaciones de viejas localizaciones y edificaciones a nuevas actividades.

De hecho, la transformación económica de la ciudad, al propiciar una reestructuración territorial, ha impulsado a la industria de la construcción, aunque también a los servicios, como es el caso del turismo destinado a los sectores de altos ingresos, sobre todo para aquellos hombres y mujeres de negocios que se mueven en los ámbitos nacionales e internacionales. Este tipo de turismo ha cobrado especial relevancia, entre otros, por la reasignación de pequeñas instalaciones de altísimo lujo a estos servicios turísticos. Hotelería, restaurantes, servicios de informática, renta de automóviles y otros servicios destinados a la producción se han expandido, generando nuevas alternativas de empleo, particularmente para los sectores de ingresos medios y altos. 
como para la determinación de las características de dichas ciudad de México

instalaciones.

A continuación, se plantean algunas ideas preliminares sobre la necesidad de implementar políticas distintas para la ciudad de las que han regido en el pasado, acordes con los procesos económicos y territoriales que la involucran y que intentamos esbozar en las páginas anteriores.

\subsection{La gestión de lo global}

En el contexto antes presentado, creemos que la gestión de la ciudad de México requiere de políticas globales o políticas que sean consideraciones a procesos globales. A continuación definimos algunas líneas, a nuestro juicio relevantes, para estas nuevas políticas, aunque no son las únicas posibles:

- La necesidad de implementar una "paradiplomacia" de la ciudad (Soldatos, 1989), es decir una gestión de las relaciones internacionales de la ciudad de México, similar a la que hacen las grandes ciudades del mundo.

- El análisis de la economía del Distrito Federal con visión de lo global, esto implica plantear metas como la de atraer a las actividades de escala global, siempre en el contexto del ordenamiento del territorio, encargado de la gestión nacional de estos procesos. La visión global debería articularse con una visión local que atienda a los procesos locales y, que esté ligada a ella en forma indisoluble.

- La gestión de lo global exigirá nuevas asignaciones o acomodos territoriales a través de la dotación de servicios especializados y de la creación de zonas ad hoc, en la misma forma que el desarrollo fordistademandó parques industriales. Esta necesidad no puede ser dejada en manos del sector empresarial, sino que exige una participación decidida del Estado, mediante una articulación de los poderes locales y federales, tanto para la selección de los sitios más adecuados,

\subsection{La gestión de la economía local}

La gestión de lo local debería pasar por una descentralización creciente de las funciones propias de la gestión económica hacia las delegaciones actuales. Una gestión exclusivamente desde el gobierno central del Distrito Federal sería en absoluto contraproducente, por el grado de centralización que esto implica. Por ello, la necesidad de remodelar las estructuras administrativas es esencial, particularmente, a través de la creación de municipios, de sistemas de gestión económica en los mismos y de la creación de consejos económicos en la ciudad.

Es necesario avanzar en la diferenciación entre aquellas actividades que pueden contemplarse en el nivel global (y que requieren de una gestión centralizada aunque concertada con los poderes locales), y aquellas otras que sólo requieren de la intervención local (como es el caso particular de las microempresas en zonas populares). Al respecto, podemos señalar que la gestión del Distrito Federal parece haberse centralizado en los últimos años a expensas de las delegaciones.

En el Estado de México ha tenido lugar un proceso similar, restando a muchos municipios la posibilidad de actuar en el nivel local. De tal suerte, muchas de las recomendaciones orientadas al Distrito Federal, encuentran eco también en la situación actual de los municipios conurbados.

Finalmente, es necesario que las políticas de las entidades federativas y las de los municipios conurbados o las delegaciones, sean concebidas e implementadas al mismo tiempo, de manera coordinada, aun cuando manifiesten diferencias políticas por sus distintos orígenes partidistas.

\section{Bibliografía}

Ascher, François (1996), Metapolis ou l'avenir des villes, Odile Jacob, París. 
Connolly, Priscilla (1993), "La reestructuración económica y la ciudad de México", en: Coulomb, René y Emilio Duhau (comp.). Dinámica urbana y procesos sociopolíticos, lecturas de actuali zación sobre la ciudad de México, CENVI-UAM Azcapotzalco, México, pp.45-70.

Departamento del Distrito Federal (1997), La ciudad de México antelos retos de la globalización, Coordinación General de Asuntos Internacionales, DDF, Ciudad de México, 81 p.

Friedmann, John (1996), "Where we stand: a decade of world city research", en: Knox, Paul L. y Peter J. Taylor (editores), World Cities in a World System, Cambridge University Press, pp. 21-47.

Fry, Earl; Lee Radebaugh y Panayotis Soldatos (1989), The New International Cities Era (The Global Activities of North American Municipal Governments), Brigham Young University, Provo, 253 p.

Gamboa de Buen, Jorge (1994), Ciudad de México: una visión, F.C.E., México, $261 \mathrm{p}$.

García Canclini, Néstor (1995), Consumidores y ciudadanos, conflitos multiculturales de la globalización, Grijalbo, México, 198 p.

Garza, Gustavo (1985), El proceso de industrialización en la ciudad de México, 1821-1970, El Colegio de México, México, 446 p.

Hernández Laos, Enrique (1984), “Las desigualdades regionales”, en: Rolando Cordera y Carlos Tello (comp.), Lasdesigualdadesen México, Siglo XXI, México, pp. 155-192.

Hiernaux, Daniel (1997), "Reinventando lo local: desafíos y poten-

cialidades territoriales de la globalización”, mimeo, U.A.M-X, $21 \mathrm{p}$.

(1996), "Desigualdades sociales y exclusión en la reestructuración económica y territorial de México", en: III Seminario Internacional Impactos Territoriales de la Reestructuración, Universidad de Andalucía, Huelva, 34 p.

- (1995), "Globalizing economies and cities: A View from Mexico“, en: Kresl, Peter Karl y Gary Gappert (editores), North American Cities and the Global Economy, Urban Affairs Annual review No 44, Sage, California, Pp.112-132.

- (1988), "La experiencia mexicana en la planeación de los grandes proyectos de inversión”, Estudios demograficos y urbanos, El Colegio de México, México, vol. 3 \#1, pp. 97-113.

Kresl, Peter Karl (1992), The urban economy and regional trade liberalization, Praeger, New York, 212 p.

Lipietz, Alain y Danielle Leborgne (1989), “Después del fordismo y su espacio”, CienciasEconómicas, Vol. IX, No.1 y 2, pp. 21-41.

Minc, Alain (1993), Le nouveau Moyen Age, París, 249 p.

Rubalcava, Rosa María y Martha Schteingart (1988), "Estructura urbana y diferenciación socioespacial en la zona metropolitana de la ciudad de México”, en: Garza, Gustavo (comp.), Atlas de la ciudad de México, DDF-El Coleigo de México, pp. 108-115.

Sassen, Saskia (1991), The global City, London, New York, Tokio, Princeton University Press, Princeton, 397 p.

Soldatos, Panayotis (1989), "Atlanta and Boston in the New International Cities Era: Does Age Matter?”, en: Fry, Earl, Lee Radebaugh y Panayotis Soldatos (comp.) The new International Cities Era: the Global activites of North American Municipal Governments, Brigham Young University; Provo, Utah, pp. 37-72. 